\title{
Is Prostate Cancer Related to Low Vitamin D Level?
}

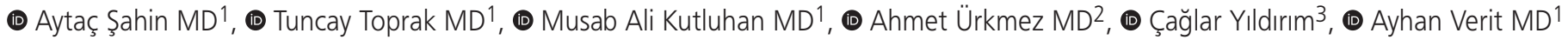 \\ 1 Fatih Sultan Mehmet Training and Research Hospital, Clinic of Urology, Istanbul, Turkey \\ 2 Haydarpaşa Numune Training and Research Hospital, Clinic of Urology, Istanbul, Turkey \\ ${ }^{3}$ Mardin State Hospital, Clinic of Urology, Mardin, Turkey
}

\begin{abstract}
Objective: Prostate cancer (PC) is the most common malignancy among men worldwide. There are several epidemiological studies linking the risk and outcome of vitamin D with PC. In this study, we aimed to compare vitamin D levels in patients with PC and benign prostatic hyperplasia (BPH). Materials and Methods: Patients with PC and BPH admitted to our urology outpatient clinic between 2017 and 2019 were included in this casecontrol study. Serum 25-hydroxyvitamin D and 1,25-dihydroxyvitamin D levels were measured to assess vitamin D status.

Results: The study was conducted with a total of 256 patients aged between 47 and 86 years between 2018-2019. The mean age of 128 patients with PC was $67.70 \pm 7.74$ years, and the mean age of 128 patients with BPH was $67.03 \pm 7.89$ years. There was a statistically significant difference between patients with PC and BPH in terms of 25-hydroxyvitamin D levels. When the patients diagnosed with PC were examined according to their subgroups, the mean 25-hydroxyvitamin D levels of 64 patients with ISUP Grade I tumors were significantly higher than the remaining 64 patients with ISUP Grade II, III and IV tumors.

Conclusion: According to our results, vitamin D levels were found to be significantly lower in patients with PC than in patients with BPH, and a significant decrease was found in vitamin D levels as the Gleason score increased. Since PC has a high prevalence and heterogeneous geographical distribution, randomized controlled trials are needed in order to demonstrate the relationship between vitamin D and cancer.
\end{abstract}

Keywords: Vitamin D, prostate cancer, benign prostatic hyperplasia

\section{Introduction}

Prostate cancer (PC) is the most common malignancy among men worldwide (1). In addition, the incidence of PC increased significantly in most Asian populations (2). New molecularly targeted therapies for PC patients have improved over the last 10 years $(3,4)$. There are a limited number of modifiable risk factors identified for PC, and further studies are needed to identify some modifiable risk factors associated with PC. There are numerous epidemiological studies linking the risk and outcome of vitamin D with PC $(5,6,7,8)$. Vitamin D is a steroid prohormone that dissolves in fat and is produced in skin by contact with sunlight. With various metabolic changes in the body, it becomes a hormone known as calcitriol, which plays an important role in calcium and phosphate metabolism. In addition to having an important role in many mechanisms in the body, Vitamin D deficiency can cause many adverse conditions.

In addition to its association with major public health problems such as obesity, diabetes, and hypertension, recent studies focus on the relationship between vitamin $D$ and cancer with increasing prevalence and types. In addition, studies have been conducted on the anti-cancer effects of vitamin D as well as the effects that suppress cancer cell growth (9). In this study, we aimed to investigate whether there is a statistically significant difference between vitamin D levels in patients with PC and patients with benign prostatic hyperplasia (BPH).

\section{Materials and Methods}

This case-control study was initiated with the approval of Fatih Sultan Mehmet Training and Research Hospital Ethics Committee (Number: FSMEAH-KAEK 2017/6, date: 12.01.2017) and each patient included in the study signed informed consent form. Patients diagnosed with PC and BPH who admitted to our urology outpatient clinic between 2017 and 2019 were included in the study. The cases were newly diagnosed, followed-up and histopathologically proven PCs. Patients with metastatic PC, recent severe weight loss, and who underwent hormonal therapy or finasteride treatment were excluded. The control group consisted of patients with lower urinary 
tract symptoms who had no pathology on digital rectal examination (DRE) and had a PSA level $<2.0 \mathrm{ng} / \mathrm{mL}$. Serum 25-hydroxyvitamin D and 1,25-dihydroxyvitamin D levels were measured to assess vitamin D status. Vitamin D concentration was evaluated by ultra-performance liquid chromatography/ tandem spectrometry analysis.

\section{Statistical Analysis}

IBM SPSS Statistics 25 program was used for statistical analysis. When evaluating the study data, the normality of the parameters was evaluated with Shapiro-Wilk test. The descriptive statistical methods included mean and standard deviation, and Student-t test was used for the comparison of parameters with normal distribution. Significance was evaluated at $p<0.05$.

\section{Results}

The study was conducted with a total of 256 patients aged between 47 and 86 years between 2018-2019. The mean age of 128 patients with PC was $67.70 \pm 7.74$ years, and the mean age of 128 patients with BPH was $67.03 \pm 7.89$ years (Table 1). There was no statistically significant difference between patients with PC and $\mathrm{BPH}$ in terms of age ( $\mathrm{p}>0.05)$.

Although the mean 1,25-dihydroxyvitamin $D$ level in patients with $\mathrm{PC}$ was lower than those with $\mathrm{BPH}$, no statistically significant difference was found ( $p>0.05$ ). There was a statistically significant difference between both groups in terms of 25-hydroxyvitamin D levels $(p=0.000)$. When the patients diagnosed with PC were examined according to their subgroups, the mean 1,25-hydroxyvitamin D levels of 64 patients with ISUP Grade I tumors were higher than the remaining 64 patients with ISUP Grade II, III and IV tumors, however, no statistically significant difference was found ( $p>0.05)$. When the patients diagnosed with PC were examined according to their subgroups, the mean 25-hydroxyvitamin D levels of 64 patients with ISUP Grade I tumors were significantly higher than the remaining 64 patients with ISUP Grade II, III and IV tumors $(\mathrm{p}<0.01)$ (Table 2$)$.

\section{Discussion}

Although vitamin D has preventive roles in many cancers, its role in the development of PC is still unclear. In the human body, vitamin D is synthesized mainly in the skin after exposure to sunlight and also vitamin $\mathrm{D}$ can be taken from some foods $(10,11)$. 25-hydroxyvitamin $D$, which is the most widely used biological form of circulating vitamin $\mathrm{D}$, is the hydroxylated

Table 1. Comparison of prostate cancer and benign prostate hyperplasia patients

\begin{tabular}{|c|c|c|c|}
\hline & PC $(n=128)$ & BPH $(n=128)$ & \multirow[t]{2}{*}{$p$ value } \\
\hline & Mean \pm SD & Mean \pm SD & \\
\hline Age (years) & $67.70 \pm 7.74$ & $67.03 \pm 7.89$ & 0.498 \\
\hline $\begin{array}{l}\text { 1,25-hydroxyvitamin D } \\
(\mathrm{ng} / \mathrm{mL})\end{array}$ & $29.42 \pm 13.99$ & $31.28 \pm 13.64$ & 0.283 \\
\hline $\begin{array}{l}\text { 25-hydroxyvitamin D } \\
(\mathrm{ng} / \mathrm{mL})\end{array}$ & $19.45 \pm 7.24$ & $26.15 \pm 8.80$ & $0.000^{*}$ \\
\hline
\end{tabular}

form of vitamin D and is widely used in clinical practice (12). It is then converted to the biologically active 1,25-hydroxyvitamin D (calcitriol) by 1-alpha-hydroxylase enzyme in the kidney and other tissues, including the prostate (13). The biomarker of vitamin $D$ in humans is mainly 25-hydroxyvitamin $D$ and partly 1,25-hydroxyvitamin D, and studies have been based on these indicators regarding vitamin $\mathrm{D}$ serum levels (14). Vitamin D serum level less than $20 \mathrm{ng} / \mathrm{mL}(50 \mathrm{nmol} / \mathrm{L})$ is defined as inadequacy (15).

In epidemiological studies on vitamin D levels of cancer patients, it is stated that these levels are less than normal values (16). Vitamin $D$ has been shown to cause dysfunction or inhibition of cell proliferation of PC cells, cell invasion, angiogenesis and altered gene expression, including c-Myc and telomerase expression, or induction of cell differentiation and apoptosis $(17,18,19,20)$. In vitro cell culture and in vivo animal studies have shown that active vitamin $D$ increases cell differentiation, inhibits cancer cell proliferation, and exhibits anti-inflammatory, pro-apoptotic and anti-angiogenic properties. In laboratory studies, it has been shown that active vitamin D inhibits the growth of cancer cells by binding to vitamin D receptor (VDR) and regulating various genes responsible for cell proliferation $(21,22,23)$. Active vitamin D stimulates the expression of cell cycle inhibitors p21 and p27, and the expression of the cell adhesion molecule E-cadherin. It inhibits the transcriptional activity of $\alpha$-catenin. Active vitamin $D$ in keratinocytes has been shown to increase repair of DNA damage caused by UVR, reduce apoptosis, and increase p53 (16). Some studies $(18,24,25,26)$ support the idea that high serum Vitamin D levels have protective effects. Other studies have shown different results $(27,28)$. In a meta-analysis focusing on the relationship between 25-hydroxyvitamin D and mortality in PC, a study of 7808 participants was conducted, and the results calculated from seven eligible studies showed a significant correlation with higher vitamin $\mathrm{D}$ levels and a reduction in all-cause mortality and a reduction in PC-related mortality. Other doseresponse analysis showed that every $20 \mathrm{nmol} / \mathrm{L}$ increase in 25-hydroxyvitamin D level was associated with a 9\% lower risk of all-cause mortality and PC-related mortality. It was concluded that high levels of circulating vitamin $\mathrm{D}$ were associated with a lower risk of PC-related mortality (29).

A meta-analysis of 21 studies by $\mathrm{Xu}$ et al. (30) found a high risk of developing $P C$ in patients with a high level of 25-hydroxyvitamin D in the serum. Sixteen studies showed a positive correlation between serum vitamin D level and PC [odds ratio $(O R)=1.17,95 \%$ confidence interval: 1.08-1.27].

\begin{tabular}{|l|l|l|l|}
\hline \multicolumn{4}{|l|}{ Table 2. Comparison of prostate cancer subgroups } \\
\hline & $\begin{array}{l}\text { ISUP 1 } \\
(\mathrm{n}=64)\end{array}$ & $\begin{array}{l}\text { ISUP 2,3,4 } \\
(\mathrm{n}=64)\end{array}$ & $\begin{array}{l}\mathrm{p} \\
\text { value }\end{array}$ \\
\cline { 2 - 3 } & Mean \pm SD & Mean \pm SD & \\
\hline $\begin{array}{l}\text { 1,25-hydroxyvitamin D } \\
(\mathrm{ng} / \mathrm{mL})\end{array}$ & $30.86 \pm 11.49$ & $27.99 \pm 16.07$ & 0.247 \\
\hline $\begin{array}{l}\text { 25-hydroxyvitamin D } \\
(\mathrm{ng} / \mathrm{mL})\end{array}$ & $22.13 \pm 7.26$ & $16.76 \pm 6.20$ & $0.000^{*}$ \\
\hline
\end{tabular}

Independent samples t-test ${ }^{*} \mathrm{p}<0.05$

ISUP: International Society of Urological Pathology, SD: Standart deviation 
In one study, it was shown that the incidence of PC was high and vitamin $\mathrm{D}$ level was low in the black race compared to other races (31). Selenium and vitamin E cancer protection research found an inverse relationship between plasma vitamin $D$ levels in high-grade cancers with a Gleason score of 7-10 (32).

In our study, there was a statistically significant difference between patients with $\mathrm{PC}$ and $\mathrm{BPH}$ in terms of mean 25-hydroxyvitamin $D$ levels $(p=0.000)$. In the PC group, 25-hydroxyvitamin $D$ levels were significantly lower. When the patients diagnosed with PC were examined according to their subgroups, the mean 25-hydroxyvitamin D levels of 64 patients with ISUP Grade I tumors were significantly higher than the remaining 64 patients with ISUP Grade II, III and IV tumors $(p<0.01)$. As the Gleason score of cancer increased, a significant decrease was found in vitamin $D$ levels.

In a study conducted since the functions of the VDR and associated vitamin D metabolic enzymes are associated with vitamin $\mathrm{D}$ levels, it was shown that nucleotide polymorphisms alone in the $3^{\prime}$-untranslated region of the VDR gene were associated with PC risk in men with low vitamin D levels (31).

In a meta-analysis of 19 prospective studies, epidemiological evidence of the tumor-promoting effect of vitamin D in PC was provided, but the effect was modest (32). However, no clear biological relationship was found between high levels of vitamin D and increased risk of PC. We can only speculate about the cause of the tumor-stimulating effect of vitamin D in PC (33). One reason for this may be that 25 -hydroxyvitamin $D$ is a sign of other factors related to PC risk. For example, insulinlike growth factor-I (IGF-1) is associated with PC $(34,35)$ and a relationship between 25 -hydroxyvitamin $\mathrm{D}$ and IGF-1 has been reported. In another study, each $10 \mathrm{ng} / \mathrm{mL}$ 25-hydroxyvitamin D increase was associated with an increased risk of PK of $23 \%$ (5). In the meta-analysis of Gilbert et al. (36), it was shown that there was a low level of evidence between low exposure to sunlight and the risk of PC $(37,38)$.

\section{Conclusion}

According to our results, vitamin D levels were found to be significantly lower in patients with PC than in patients with $\mathrm{BPH}$. In addition, when the cancer group was evaluated among themselves, a significant decrease was found in vitamin D levels as the Gleason score increased. Although there is no relationship between vitamin D and PC in most studies, there are studies in the literature showing an inverse relationship. Since PC has a high prevalence and heterogeneous geographical distribution, randomized controlled trials are needed in order to demonstrate the relationship between vitamin D and cancer.

\section{Ethics}

Ethics Committee Approval: This case-control study was initiated with the approval of Fatih Sultan Mehmet Training and Research Hospital Ethics Committee (Number: FSMEAH-KAEK 2017/6, date: 12.01.2017).

Informed Consent: Each patient included in the study signed informed consent form.

Peer-review: Internally and externally peer-reviewed.

\section{Authorship Contributions}

Surgical and Medical Practices: A.Ş., M.A.K., Concept: A.Ü., Design: T.T., Data Collection or Processing: A.Ş., Ç.Y., Analysis or Interpretation: A.V., A.Ü., Literature Search: A.Ş., Writing: A.Ş.

Conflict of Interest: No conflict of interest was declared by the authors.

Financial Disclosure: The authors declared that this study received no financial support.

\section{References}

1. Attard G, Parker C, Eeles RA, et al. Prostate cancer. Lancet 2016;387:70-82.

2. Ito K. Prostate cancer in Asian men. Nat Rev Urol 2014;11:197-212.

3. Ritch $\mathrm{CR}$, Cookson MS. Advances in the management of castration resistant prostate cancer. BMJ 2016;355:4405.

4. Yap $T A$, Smith $A D$, Ferraldeschi $R$, et al. Drug discovery in advanced prostate cancer: trans $\neg$ lating biology into therapy. Nat Rev Drug Discov 2016;15:699-718.

5. Jackson MD, Tulloch-Reid MK, Lindsay $\mathrm{CM}$, et al. Both serum 25-hydroxyvitamin $D$ and calcium levels may increase the risk of incident prostate cancer in Caribbean men of African ancestry. Cancer Med 2015;4:925-935.

6. John EM, Schwartz GG, Koo J, et al. Sun exposure, vitamin D receptor gene polymorphisms and risk of advanced prostate cancer. Cancer Res 2005;65;5470-5479.

7. John EM, Koo J, Schwartz GG. Sun exposure and prostate cancer risk: evidence for a protective effect of early-life exposure. Cancer Epidemiol Biomarkers Prev 2007;16;1283-1286.

8. Schwartz GG, Hanchette CL. UV, latidude and spatial trends in prostate cancer mortality: all sunlighjt is not the same (United States). Cancer Causes Control 2006;17:1091-1101.

9. Clinckspoor I, Verlinden L, Mathieu C, et al. Vitamin D in thyroid tumorigenesis and development. Prog Histochem Cytochem 2013;48:65-98.

10. Bandera Merchan B, Morcillo S, Martin-Nunez G, et al. The role of vitamin $D$ and VDR in carcinogenesis: through epidemiology and basic sciences. J Steroid Biochem Mol Biol 2016;167:203-218.

11. Trummer $C$, Pandis $M$, Verheyen N, et al. Beneficial effects of UVradiation: vitamin $\mathrm{D}$ and beyond. Int J Environ Res Public Health 2016:13.

12. Batai $K$, Murphy $A B$, Nonn L, Kittles RA. Vitamin D and immune response: implications for prostate cancer in African Americans. Front Immunol 2016;7:53.

13. Donkena KV, Karnes RJ, Young CY. Vitamins and prostate cancer risk. Molecules 2010:15;1762-1783.

14. Zerwekh JE. Blood biomarkers of vitamin D status. Am J Clin Nutr 2008;87:1087-1091.

15. Baysal A. Beslenme. Ayşe Baysal, 14. baskı, Ankara: Hatipoğlu Yayınları, 2012:176-83.

16. Wesa KM, Segal NH, Cronin AM, et al. Serum 25-Hydroxy Vitamin $\mathrm{D}$ and Survival in Advanced Colorectal Cancer: A Retrospective Analysis. Nutr Cancer 2015;67:424-430.

17. Ingraham BA, Bragdon B, Nohe A. Molecular basis of the potential of vitamin D to prevent cancer. Curr Med Res Opin 2008;24:139-149.

18. Gupta D, Lammersfeld CA, Trukova K, Lis CG. Vitamin D and prostate cancer risk: a review of the epidemiological literature. Prostate Cancer Prostatic Dis 2009;12:215-226.

19. Rohan JN, Weigel NL. 1Alpha,25-dihydroxvitamin D3 reduces c-Myc expression, inhibiting proliferation and causing G1 accumulation in C4-2 prostate cancer cells. Endocrinology 2009;150;2046-2054. 
20. Gocek E, Studzinski GP. Vitamin D and differentiation in cancer. Crit Rev Clin Lab Sci 2009;46:190-209.

21. Manson JE, Mayne ST, Clinton SK. Vitamin D and prevention of cancer--ready for prime time? N Engl J Med 2011;364:1385-1387.

22. Krishnan AV, Feldman D. Mechanisms of the anticancer and antiinflammatory actions of vitamin D. Annu Rev Pharmacol Toxicol 2011; $51: 311-336$

23. Bikle D. Nonclassic Actions of Vitamin D. J Clin Endocrinol Metab 2009;94:26-34.

24. Mucci LA, Spiegelman D. Vitamin D and Prostate cancer risk--a less sunny outlook? J Natl Cancer Inst 2008;100:759-761.

25. van der Rhee $H$, Coebergh JW, de Vries E. Sunlight, vitamin D and the prevention of cancer: a systematic review of epidemiological studies. Eur J Cancer Prev 2009;18:458-475.

26. Trump DL, Chadha MK, Sunga AY, et al. Vitamin D deficiency and insufficiency among patients with prostate cancer. BJU Int 2009;104:909-914.

27. Travis RC, Crowe FL, Allen NE, et al. Serum vitamin D and risk of prostate cancer in a case-control analysis nested within the European Prospective Investigation into Cancer and Nutrition (EPIC). Am J Epidemiol 2009;169;1223-1232.

28. Ahn J, Peters U, Albanes D, et al. Serum vitamin D concentration and prostate cancer risk: a nested case-control study. J Natl Cancer Inst 2008; 100:796-804.

29. Song ZY, Yao Q, Zhuo Z, et al. Circulating vitamin D level and mortality in prostate cancer patients: a dose-response meta-analysis. Endocr Connect 2018;7:294-303.
30. Xu Y, Shao X, Yao Y, et al. Positive association between circulating 25-hydroxyvitamin $D$ levels and prostate cancer risk: new findings from an updated meta-analysis. J Cancer Res Clin Oncol 2014; 140:1465-1477.

31. Park SY, Cooney RV, Wilkens LR, et al. Plasma 25-hydroxyvitamin D and prostate cancer risk: the Multiethnic Cohort. Eur J Cancer 2010;46:932-936.

32. Kristal AR, Till C, Song $X$, et al. Plasma vitamin $D$ and prostate cancer risk: results from the Selenium and Vitamin E Cancer Prevention Trial. Cancer Epidemiol Biomarkers Prev 2014;23:1494-1504.

33. Ahn J, Albanes D, Berndt SI, et al. Vitamin D related genes, serum vitamin D concentrations and prostate cancer risk. Carcinogenesis 2009;30:769-776.

34. Gao J, Wei W, Wang G, et al. Circulating vitamin D concentration and risk of prostate cancer: a döşe-response meta-analysis of prospective studies. Ther Clin Risk Manag 2018;14: 95-104.

35. Meyer $\mathrm{HE}$, Robsahm TE, Bjorge $\mathrm{T}$, et al. Vitamin $\mathrm{D}$, season, and risk of prostate cancer: a nested case-control study within Norwegian health studies. Am J Clin Nutr 2013;97:147-154.

36. Gilbert R, Metcalfe C, Oliver SE, et al. Life course sun exposure and risk of prostate cancer: population-based nested case-control study and meta-analysis. Int J Cancer 2009;125:1414-1423.

37. Chan JM, Stampfer MJ, Ma J, et al. Insulin-like growth factor-I (IGF-I) and IGF binding protein-3 as predictors of advanced-stage prostate cancer. J Natl Cancer Inst 2002;94:1099-1106.

38. Stattin P, Bylund A, Rinaldi S, et al. Plasma insulin-like growth factor-I, insulin-like growth factor-binding proteins, and prostate cancer risk: a prospective study. J Natl Cancer Inst 2000;92:1910-1917. 